\title{
Immune Function in Alcoholism: A Controlled Study
}

\author{
Ziad Kronfol, Madhavan Nair, Elizabeth Hill, Philip Kroll, Kirk Brower, and John Greden
}

\begin{abstract}
Several studies have shown an increased risk for infection and cancer in alcoholic patients. The mechanisms for such observations remain largely unknown. In an effort to investigate the possibility of immunological dysfunction in alcoholism, we studied three immune parameters in $\mathbf{4 7}$ hospitalized chronic alcoholic patients and 47 ageand sex-matched normal controls. The immune measures were: (1) lymphocyte phenotyping, with estimates of percentages of $\mathrm{T}$ cellis, $B$ cells, $T$ helpers, $T$ suppressors, natural killer (NK) cells, and cells carrying the activation markers $\mathrm{IL}_{2} \mathrm{R}_{1}$ and $\mathrm{I}_{2} ;(2) \mathrm{NK}$ cell activity; and (3) lymphokine-activated killer cell activity. Results indicate a significant increase in the $\mathrm{IL}_{2} R$ and $\mathrm{I}_{2}$ lymphocyte markers in alcoholic patients compared with matched controls. We also found a nonsignificant trend for a decrease in the percentage of suppressor $T$ cells in the alcoholic group, as well as a trend for a negative correlation between the percentage of $\mathrm{T}$ suppressor cells and age. There were no significant differences in either NK or lymphokine-activated killer cell activities between the two groups. Furthermore, there were no significant associations between duration and intensity of alcohol consumption and any of the immune measures. These results suggest subtle alterations in immune regulation in alcoholic patients that cannot be explained solely on the basis of duration and/or amount of alcohol consumed.

Key Words: Alcohol, Immunity, Lymphocyte Phenotype, Lymphokine-activated Killer Cytotoxicity, Natural Killer Cytotoxicity.
\end{abstract}

GEVERAL REPORTS have indicated an increased risk $N$ of infection and cancer in alcoholic patients. ${ }^{1-3} \mathrm{Al}-$ though the mechanisms for such an association remain largely unknown, a reasonable assumption has been that alcohol impairs the immune system and weakens the host's defense mechanisms, thus increasing the risk of infection and cancer in otherwise predisposed individuals. Research on the effects of alcohol on the immune system however has yielded mixed results. In vitro studies seem to indicate that alcohol at lower concentrations may actually enhance natural killer (NK) activity. ${ }^{4.5}$ At higher concentrations, the effects of alcohol are uniformly immunosuppressive. ${ }^{6.7}$ Results from animal studies have similarly shown both enhancement and suppression of different immunological parameters. Bagasra et al. ${ }^{8}$ found elevated plaque-forming cells and antibody responses to antigens in alcohol-fed animals compared with matched controls. This immunnoenhancement, however, turned into immunosuppression as the duration of ethanol inges-

From the Department of Psychiatry and the Alcohol Research Center, University of Michigan, Ann Arbor, Michigan.

Received for publication May 27, 1992; accepted October 19, 1992

This work was supported in part by U.S. Public Health Service grants 1P50-AA07378 and 2RO1-MH42988.

Reprint requests: Ziad Kronfol, M.D., Department of Psychiatry, University of Michigan Medical Center, AGH-9D, Box 0118, 1500 East Medical Center Drive, Ann Arbor, MI 48109-0118.

Copyright (C) 1993 by The Research Society on Alcoholism. tion increased. Other investigators have shown either an increase, ${ }^{9}$ no change, ${ }^{10}$ or a decrease ${ }^{11,12}$ in NK activity in alcohol-consuming animals compared with controls. $\mathrm{Hu}-$ man studies are relatively few, and possible confounding variables are many. Charpentier et al. ${ }^{13}$ found an impairment in lymphocyte NK cell activity in chronic alcoholics, but only in those with active liver cirrhosis, and particularly those with severe malnutrition. Irwin et al. ${ }^{14}$ confirmed the reduction in NK activity in alcoholics, even in those without evidence of liver cirrhosis or malnutrition, but found no clear relation with the amount of alcohol consumed. Saxena et al., ${ }^{15}$ on the other hand, reported increased NK activity in lymphocytes from alcoholic subjects in spite of nutritional deficiencies and other drug addictions. Other studies have shown that immune parameters, including NK activity, were not significantly different in alcoholic patients and normal controls. ${ }^{16}$

In this study, we report our immunological findings on hospitalized chronic alcoholic patients and age- and sexmatched normal controls. Patients and control were given several immunological tests, including lymphocyte phenotyping with monoclonal antibodies and functional assays of both NK and lymphokine-activated killer (LAK) cell activities. Both patients and controls were also given extensive clinical and demographic assessments, with emphasis on duration and quantity of alcohol use.

\section{METHODS}

Subjects for the study were 47 alcoholic patients and 47 age- and sexmatched normal controls. All alcoholic patients were screened by the University of Michigan Alcohol Research Center and were hospitalized at one of the University of Michigan alcohol treatment facilities. Screening by the Alcohol Research Center was done by trained personnel and consisted of an extensive evaluation of clinical and demographic features, with special emphasis on drinking behavior. Each patient was age- and sex-matched with a normal control. Both patients and controls were evaluated with a structured psychiatric interview, the Diagnostic Interview Schedule, ${ }^{17}$ from which a DSM-III- $\mathrm{R}^{-18}$ diagnosis was made. All patients met DSM-III-R criteria for alcohol abuse and/or dependence as reflected in the Diagnostic Interview Schedule interview. No other psychiatric diagnosis was made. None of the normal controls met criteria either past or present for any psychiatric diagnosis. Both patients and controls were relatively healthy and free of severe medical illness known to interfere with immune regulation. Illnesses that were considered exclusionary criteria included cancer, systemic infection, stroke, insulindependent diabetes mellitus, liver cirrhosis, and the like. Thirteen patients were drug-free. The remainder were taking one or more pharmacological agents, including psychotropic medications. Immune-related medications, such as antiinfectious and antiinflammatory medications, were not allowed. Drinking severity was assessed with estimates of lifetime average drinks per day and years of heavy drinking. Mood states were rated with the Hamilton Rating Scale for Depression (HRSD) ${ }^{19}$ and the Profile of 
Mood States (POMS). ${ }^{20}$ In addition, severity of life events was assessed with the Holmes and Rahe life events schedule ${ }^{21}$ and a line scale for the perception of stress. 22

\section{Lymphocyte Separation}

Blood samples from both patients and age- and sex-matched normal controls were drawn between 8:00 and 9:00 in the morning in heparinized tubes. Lymphocytes were separated by a modified method of Boyum. ${ }^{23}$ Blood was diluted with an equal volume of phosphate-buffered saline (PBS) and centrifuged at $400 \times \mathrm{g}$ for $30 \mathrm{~min}$ at room temperature over a cushion of Ficoll-Hypaque solution. The mononuclear cells were then harvested, washed three times with PBS, and resuspended in RPMI 1640 medium containing $25 \mathrm{~mm}$ HEPES buffer supplemented with $10 \%$ heatinactivated fetal calf serum (Gibco, Grand Island, NY), $80 \mu \mathrm{g} / \mathrm{ml}$ gentamicin (Schering Corp., Kenilworth, NJ), and $300 \mu \mathrm{g}$ fresh glutamine $/ \mathrm{ml}$ (complete medium). Mononuclear cells were depleted of adherent monocytes by passage over a column of Sephadex G-10 beads (Pharmacia Fine Chemicals, Piscataway, NJ) equilibrated in the same complete medium. The cell recovery was $>70 \%$ of the total input, and monocyte contamination as indicated by nonspecific esterase staining was $<2 \%$.

\section{Lymphocyte Phenotyping}

For the lymphocyte phenotyping, $10^{6}$ lymphocytes from each subject and matched control were washed and incubated separately with the following commercially available monoclonal antibodies (Coulter Immunology, Hialeah, $\mathrm{FL}$ ): $\mathrm{CD}_{2}$ (total $\mathrm{T}$ cells), $\mathrm{CD}_{4}$ (helper/inducer $\mathrm{T}$ cells), $\mathrm{CD}_{8}$ (suppressor/cytotoxic $\mathrm{T}$ cells), $\mathrm{CD}_{20}$ (total $\mathrm{B}$ cells), $\mathrm{CD}_{36}$ (NK cells), and the activation markers $\mathrm{IL}_{2} \mathrm{R}_{1}$ (defining the receptor for interleukin-2) and $I_{2}$ (an HLA-D/DR related Ia-like antigen). In addition to these monoclonal antibodies, a negative control of mouse IgG was used to provide a baseline for flow cytometry. The cells were incubated with $10 \mu \mathrm{l}$ of the respective monoclonal antibodies at $4^{\circ} \mathrm{C}$ for $30 \mathrm{~min}$. Following incubation the cells were washed three times with MEM medium containing $2 \%$ fetal calf serum and then fixed with $1 \%$ formalin in PBS. The labeled and fixed cells were later analyzed by flow cytometry with the fluorescein-activated cell sorter (EPICS), a core facility at the University of Michigan Medical Center.

\section{Assay of NK Activity}

NK activity was determined in a direct ${ }^{51} \mathrm{Cr}$ release assay as previously described. ${ }^{24}$ Briefly, a fixed number of viable effector cells were prepared in varying dilutions to give 50:1, 25:1, 12.5:1, 6.25:1, and 3.125:1 effector to target (E:T) cell ratios. Effector cells were added to triplicate cultures of ${ }^{51} \mathrm{Cr}$-labeled target cells (K562 cell line) in a final volume of $0.2 \mathrm{ml}$ in $\mathrm{V}$ bottom microtiter plates (Dynatech Labs, Alexandria, VA). After centrifugation at $40 \times g$ for $5 \mathrm{~min}$, they were incubated at $37^{\circ} \mathrm{C}$ in a humidified atmosphere of $5 \% \mathrm{CO}_{2}$ in air for $4 \mathrm{hr}$. At the end of incubation, plates were spun at $400 \times g$ for $5 \mathrm{~min}$, and $100 \mu 1$ aliquots of supernatants were removed from each well and transferred to glass tubes to be read in a Packard model 593 gamma counter. Percentage of cytotoxicity was calculated as follows:

$$
\% \text { cytotoxicity }=\frac{\text { experimental release }- \text { spontaneous release }}{\text { total release }- \text { spontaneous release }} \times 100 \text {, }
$$

where spontaneous release represents count released from control wells containing only $1 \times 10^{4}$ target cells. Cytotoxicity is also expressed as lytic units (LUs) per $10^{7}$ effector cells. A LU is defined as the number of effector cells needed to yield $30 \%$ cytotoxicity of $1 \times 10^{4}$ target cells. LUs are calculated from the cytotoxicity curve for each test by linear regression analysis as described. ${ }^{25}$

\section{Assay of LAK Cell Activity}

LAK cell activity assays were performed as described. ${ }^{26}$ Briefly, a fixed number of cells from the lymphocyte preparation was incubated for 5 days in a complete medium to which 10 units $/ \mathrm{ml}$ of human recombinant interleukin-2 (Collaborative Biomedical Products, Inc., Lexington, MA) was added to generate LAK cells. LAK cell cytotoxicity was then assessed using a standard $4-\mathrm{hr}{ }^{51} \mathrm{Cr}$ release assay against $\mathrm{SB}$, an NK-resistant human leukemia B cell line. A control culture that was not treated with IL-2 produced $<5 \%$ of total ${ }^{51} \mathrm{CR}$ release. ${ }^{26}$ Results are expressed as percentage of cytotoxicity, as with the NK assays.

\section{Statistical Analysis}

The primary data analysis compared patients and their matched control subjects on demographic, clinical, and immunological measures (lymphocyte phenotyping, NK and LAK cell activities). Paired $t$ tests were used for all of these comparisons, with a Bonferroni correction for multiple tests, where indicated. Differences in NK activity were analyzed with paired $t$ tests both on the individual percentage cytotoxicities for each E:T ratio, as well as on the natural logarithm of the LU calculated with a SAS NLIN program courtesy of Dr. Eda Bloom. ${ }^{25}$ LAK cell activity was tested by paired $t$ test on the percentage of cytotoxicity for the four different E:T ratios used. Variables expressed as percentages were reanalyzed after arcsin transformation. Transformation made no appreciable difference in the analysis results; therefore, nontransformed results are presented herein, except for the case of NK LUs. Pearson correlation coefficients were calculated between clinical variables and the immunological measures that differed between patients and their matched controls.

Numbers of patient-control pairs varied for lymphocyte phenotyping and other laboratory tests. Although 47 pairs were studied, accurate LU measures for the NK assay were available for 42 pairs. LAK cell assays were available for 11 pairs. Most lymphocyte subsets were available for 36 pairs, but $I_{2}$ and $I L_{2} R_{1}$ were added later and are presented here for 15 pairs only.

\section{RESULTS}

Demographic and clinical features for both the alcoholic patients and the normal controls are presented in Table 1. There were no significant differences in either age or sex distribution, because patients were age- and sexmatched with normal controls. As expected, the alcoholic patients had a significantly higher average number of drinks per day $(t=7.653 ; p<0.0001)$; they also had a significantly longer duration of heavy drinking $(t=6.997$; $p<0.0001$ ). There were, however, no significant differences in days since last drink between alcoholic patients and their matched controls $(t=-1.663 ; p>1.0)$. Furthermore, alcoholic patients scored significantly higher on the HRSD $(t=4.525 ; p<0.0001)$ and the POMS depression subscale $(t=4.980 ; p<0.0001)$. They also reported

Table 1. Demographic and Clinical Features in Alcoholic Patients and Normal Controls

\begin{tabular}{lccc}
\hline \multicolumn{1}{c}{ Variable } & $\begin{array}{c}\text { Alcoholic } \\
\text { patients } \\
(n=47)\end{array}$ & $\begin{array}{c}\text { Normal } \\
\text { controls } \\
(n=47)\end{array}$ & Significance \\
\hline Age & $50.6 \pm 12.9$ & $51.9 \pm 12.3$ & NS \\
Sex (M/F) & $39 / 8$ & $39 / 8$ & NS \\
Lifetime average drinks/day & $7.5 \pm 4.0$ & $1.8 \pm 0.9$ & 0.0001 \\
Years heavy drinking & $12.3 \pm 10.7$ & $0 \pm 0$ & 0.0001 \\
Days since last drink & $5.7 \pm 5.1$ & $12.4 \pm 24.6$ & NS \\
Hamilton total & $4.7 \pm 5.4$ & $0.4 \pm 1.2$ & 0.0001 \\
POMS depression & $13.7 \pm 13.4$ & $2.5 \pm 4.0$ & 0.0001 \\
Life events & $187.7 \pm 132$ & $86.7 \pm 82.1$ & 0.0001 \\
\hline
\end{tabular}

Results are expressed as mean \pm SD. NS, not statistically significant. 
significantly more stressful life events $(t=3.493 ; p<$ 0.0001 ), as reflected by their scores on the Holmes and Rahe scales.

Results of the lymphocyte phenotyping are presented in Table 2. There were no significant differences in the percentage of T cells, B cells, or NK cells between the two groups. There was a suggestion that alcoholic patients may have a lower percentage of suppressor cells $\mathrm{CD}_{8}(t=1.923$; $p=0.063$ ), and a trend toward higher helper-suppressor $\mathrm{T}$ cell ratios $\mathrm{CD}_{4} / \mathrm{CD}_{8}(t=1.989 ; p=0.0545)$. Further, we found significantly higher percentages of lymphocytes carrying the activation markers $\mathrm{IL}_{2} \mathrm{R}_{1}(t=-2.599 ; p=$ 0.022 ) and significantly higher percentages of lymphocytes carrying the activation marker $\mathrm{I}_{2}(t=-3.422 ; p=0.005)$ in alcoholic patients compared with their matched controls.

Figure 1 shows the results of the functional assays comparing NK activity between the alcoholic patients and their matched controls. Differences in percentage cytotoxicity between the two groups were not statistically significant for any of the E:T ratios used. The corresponding $t$

Table 2. Lymphocyte Subsets in Alcohol Patients and Normal Controls

\begin{tabular}{lccc}
\hline \multicolumn{1}{c}{ Lymphocyte marker } & $\begin{array}{c}\text { Alcoholic } \\
\text { patients }\end{array}$ & $\begin{array}{c}\text { Normal } \\
\text { controls }\end{array}$ & Significance \\
\hline $\mathrm{CD}_{2}$ (total T) & $61.2 \pm 14.8$ & $63.3 \pm 13.9$ & $\mathrm{NS}$ \\
$\mathrm{CD}_{4}$ (T helper/inducer) & $41.1 \pm 13.6$ & $40.9 \pm 12.1$ & $\mathrm{NS}$ \\
$\mathrm{CD}_{8}$ (T supressor/cytotoxic) & $20.2 \pm 8.8$ & $24.2 \pm 9.4$ & 0.063 \\
$\mathrm{CD}_{4} / \mathrm{CD}_{\mathrm{a}}$ & $2.6 \pm 1.8$ & $1.9 \pm 0.9$ & 0.0545 \\
$\mathrm{CD}_{20}$ (total B) & $7.6 \pm 5.9$ & $6.3 \pm 4.1$ & $\mathrm{NS}$ \\
$\mathrm{CD}_{68}$ (NK cells) & $11.8 \pm 7.6$ & $12.3 \pm 10.0$ & $\mathrm{NS}$ \\
$\mathrm{IL}_{2} \mathrm{R}_{1}$ (interleukin-2 receptor) & $9.0 \pm 4.5$ & $5.5 \pm 3.0$ & 0.022 \\
$\mathrm{~L}_{2}$ (HLA-D/DR-related la-like antigen) & $15.6 \pm 4.8$ & $9.6 \pm 4.1$ & 0.005 \\
\hline
\end{tabular}

Results are expressed in percentages (mean \pm SD). NS, not statistically significant.

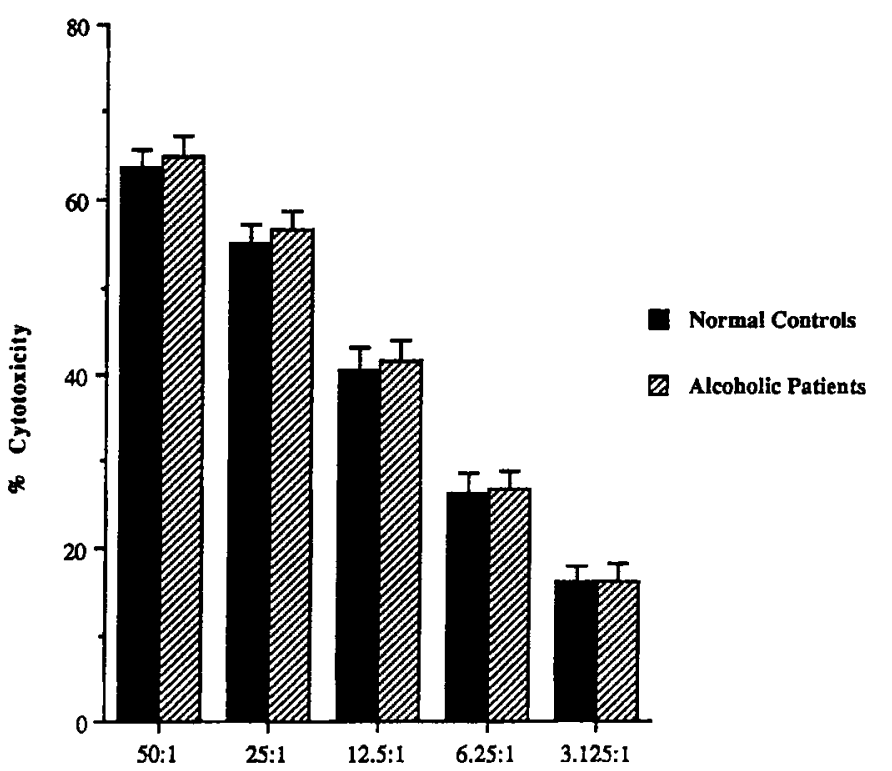

E:T Ratios

Fig. 1. Lymphocyte NK cell activity in alcoholic patients and matched normal controls. Results are expressed in percentage cytotoxicity (mean $\pm \mathrm{SE}$ ) against K562 cells for the different E:T ratios used. No significant differences between patients and controls were observed. and $p$ values for the $5 \mathrm{E}: \mathrm{T}$ ratios were $t=0.406, p=0.688$; $t=0.492, p=0.626 ; t=0.261, p=0.795 ; t=0.199, p=$ 0.843 and $t=0.289, p=0.774$, respectively. Similarly, no significant differences were found when the results were expressed in LUs $(t=-0.412, p=0.683)$.

Comparisons of LAK cell activities between alcoholic patients and matched controls are shown in Fig. 2. Here again, there were no significant differences between the two groups for any of the E:T ratios examined. Corresponding $t$ and $p$ values for the $4 \mathrm{E}: \mathrm{T}$ ratios were $t=$ $-0.706, p=0.495 ; t=-0.745, p=0.469 ; t=-1.035, p$ $=0.323$; and $t=-1.455, p=0.206$, respectively.

Because age has often been found to correlate negatively with different immune variables, we examined the potential effects of age on the distribution of the different lymphocyte subsets, as well as the effects of age on both NK and LAK cell activities. There were no significant associations between patient age and any of the immune variables studied. We did, nevertheless, find a nonsignificant negative association between age and $\mathrm{CD}_{8}(r=$ $-0.289 ; p=0.087$ ) in the alcoholic patients but not among the control subjects. There were also no significant differences in immune measures between medicated and unmedicated patients. Furthermore, there were no significant associations between $\mathrm{CD}_{8}, \mathrm{IL}_{2} \mathrm{R}_{1}$ or $\mathrm{I}_{2}$ and any of the clinical variables in either the alcoholic patients or the normal controls (data not shown).

\section{DISCUSSION}

This study was undertaken to assess key immune parameters in hospitalized chronic alcoholic patients com-

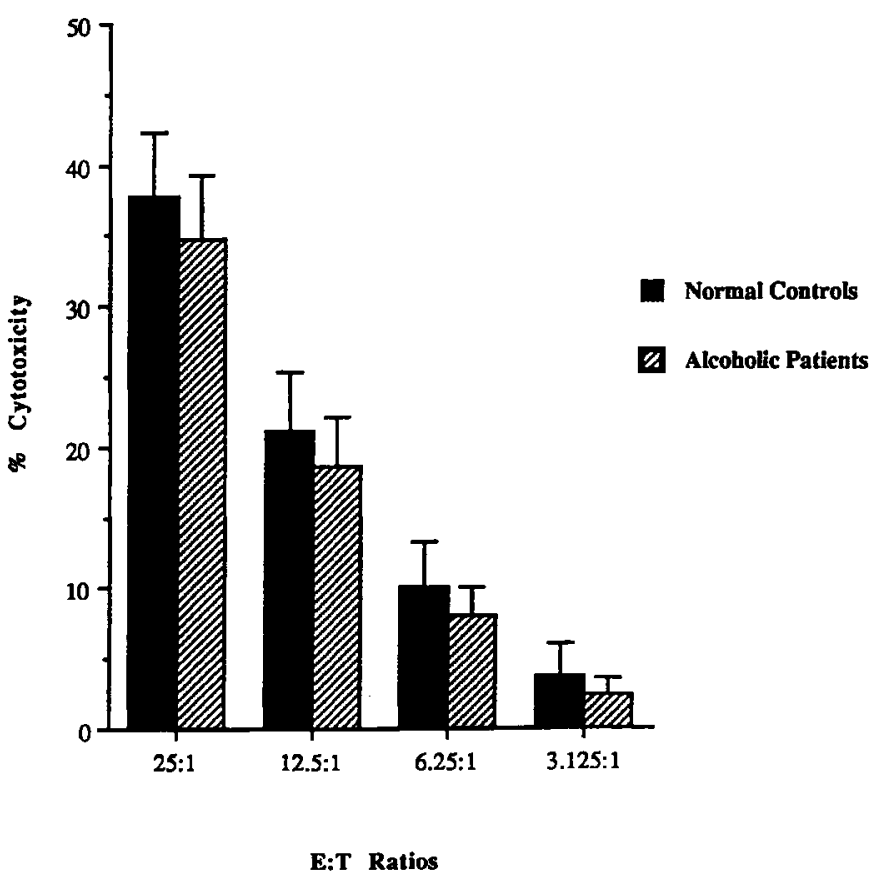

Fig. 2. LAK cell activity in alcoholic patients and matched normal controls. Results are expressed in percentage cytotoxicity (mean \pm SE) against the NKresistant SB cells for the different $E: T$ ratios used. No significant differences between patients and controls were observed. 
pared with age- and sex-matched normal controls. The immunological assessment included lymphocyte phenotyping with monoclonal antibodies representing the major lymphocyte subsets ( $\mathrm{T}$ cells, B cells, NK cells, T helpers, and $T$ suppressors), as well as the activation markers $I L_{2} R_{1}$ and $\mathrm{I}_{2}$. In addition to the lymphocyte phenotyping, the immunological assessment included two functional assays: NK and LAK cell activities. Each patient was age- and sex-matched with a normal control, and all immune assays were performed simultaneously on fresh blood samples from patients and their respective controls to minimize the potential effects of interassay variation. In addition, we collected extensive demographic and clinical data, including potential confounding variables, such as depression and stress on both patients and controls.

Results of the specific lymphocyte subsets show no significant differences between alcoholic patients and matched normal controls. Similarly, there were no significant differences between these two groups in either NK or LAK cell activities. These data are consistent with previously published reports. ${ }^{16}$ Our data also reveal no significant associations between patient age and any of the immune variables under investigation. There was, however, a nonsignificant trend for a negative association between age and the percentage of $T$ suppressor cells in alcoholic patients but not in controls. Again, these findings are consistent with published reports suggesting a decline in several immune parameters with age, but not necessarily in $\mathrm{CD}_{4} / \mathrm{CD}_{8}$ ratios ${ }^{27}$ or $\mathrm{NK}$ activity. ${ }^{28}$

Our results also indicate a significant increase in the activation markers $\mathrm{IL}_{2} \mathrm{R}_{1}$ and $\mathrm{I}_{2}$ among alcoholic patients compared with matched normal controls. This activation seems to be independent of the duration of drinking, amount of alcohol consumed, or time elapsed since last drink. Alcoholic patients were also significantly more depressed, and experienced significantly more stressful life events, but there were no significant associations between either $\mathrm{IL}_{2} \mathrm{R}_{1}$ or $\mathrm{I}_{2}$ and HRSD scores, POMS depression scores, or Life Events scores (data not shown). Alcoholic patients may also suffer from a variety of medical problems, including nutritional deficiencies and liver disease. In this study, however, patients with malnutrition or severe liver disease, including liver cirrhosis, were excluded. Patients with other serious medical illness were also excluded. It is therefore possible that the use of alcohol may activate certain types of lymphocytes resulting in a larger number of lymphocytes in alcoholic patients expressing the activation markers $\mathrm{IL}_{2} \mathrm{R}_{1}$ or $\mathrm{I}_{2}$. It is also possible that a defect may arise in the binding of the monoclonal antibodies to the $I_{2} R_{1}$ and $I_{2}$ in the alcoholic patients resulting in nonspecific and therefore increased binding to these antibodies. Still another possibility is that the alcoholic patients may express increased activation antigens in response to nonspecific insults to the immune system possibly related to subclinical inflammation or infection associated with alcoholism. Further research needs to be conducted to consider these possibilities.

In summary, we have compared lymphocyte phenotyping, NK and LAK cell activities in a group of hospitalized chronic alcoholic patients and individually matched ageand sex-matched normal controls. Alcoholic patients had a significant increase in the percentage of the activation markers $I L_{2} R_{1}$ and $I_{2}$. There were, however, no significant differences in either NK or LAK cell activities between the two groups. These studies suggest subtle alterations in immune regulation in alcoholic patients compared with matched controls. The clinical significance of these observations remains to be determined.

\section{REFERENCES}

1. Adams HG, Jordan C: Infections in the alcoholic. Med Clin North Am 68:179-202, 1984

2. Smith FE, Palmer DL: Alcoholism, infection and altered host defenses. A review of clinical and experimental observations. J Chronic Dis 29:35-49, 1976

3. Pollak ES, Nomura A, Helburn LK, et al: Prospective study of alcohol consumption and cancer. N Engl J Med 310:617-621, 1984

4. Rice C, Hidig D, Lad P, Mendelson J: Ethanol activation of human natural cytotoxicity. Immunopharmacology 6:303-316, 1983

5. Kendall RA, Tarjan S: The dual effect of prostoglandin and ethanol on the natural killer cytolytic process: Effector activation and NK-cell-target cell conjugation lytic inhibition. J Immunol 125:27702777,1980

6. Stacey NH: Inhibition of antibody dependent cell mediated cytotoxicity by ethanol. Immunopharmacology 8:155-162, 1984

7. Ristow SS, Starkey VR, Hass GM: Inhibition of natural killer cell activity in vitro by alcohol. Biochem Biophy Res Commun 105:13151321,1982

8. Bagasra O, Howeedy A, Dorio R, Kajdacsy-Balla A: Functional analysis of T-cell subsets in chronic experimental alcoholism. Immunology 61:63-69, 1987

9. Saxena IB, Saxena RK, Adler WH: Regulation of natural killer activity in vivo: Part IV. High natural killer activity in alcohol drinking mice. Indian J Exp Biol 19:1001-1006, 1981

10. Abdallah RM, Starkey JR, Meadows GG: Alcohol and related dietary effects on mouse natural killer cell activity. Immunology 50:131137,1983

11. Walia AS, Pruitt KM, Rodgers JD, Lamon EW: In-vitro effect of ethanol on cell-mediated cytotoxicity by murine spleen cells. Immunopharmacology 13:11-24, 1987

12. Meadows GG, Blank SE, Duncan DD: Influence of ethanol consumption on natural killer cell activity in mice. Alcohol Clin Exp Res 13:476-479, 1989

13. Charpentier B, Franco D, Paci L, et al: Deficient natural killer cell activity in alcoholic cirrhosis. Clin Exp Immunol 58:107-115, 1984

14. Irwin $M$, Caldwell $C$, Smith $T$, et al: Major depressive disorder, alcoholism, and reduced natural killer cell cytotoxicity. Arch Gen Psychiat 47:713-719, 1990

15. Saxena QP, Mezey E, Adler W: Regulation of natural killer cell activity in vivo. II. The effect of alcohol consumption on human peripheral blood natural killer cell activity. Int J Cancer 26:413-417, 1980

16. Ericsson $\mathrm{CD}$, Kohl S, Pickering LK, et al: Mechanisms of host defense in well nourished patients with chronic alcoholism. Alcohol Clin Exp Res 4:261-265, 1980

17. Robins LN, Helzer JE, Croughan J, Ratcliff KS: The National Institute of Mental Health Diagnostic Interview Schedule. Arch Gen Psychiat 38:381-389, 1981

18. Diagnostic and Statistical Manual of Mental Disorders, revised. American Psychiatric Association, Washington, DC, 1987 
19. Hamilton M: A rating scale for depression. J Neurol Neurosurg Psychiat 23:56-62, 1960

20. McNair D, Lorr M, Droppleman L: Profile of Mood States (Manual). San Diego, Educational and Industrial Testing Services, 1971

21. Holmes TH, Rahe RH: The social readjustment rating scale, J Psychosom Res 11:213-218, 1967

22. Linn MW: A global assessment of recent stress (GARS) scale. Int J Psychiat Med 15:47-59, 1985

23. Boyum A: Isolation of mononuclear cells and granulocytes from human blood. Scand J Clin Lab Invest 21(Suppl. 97): 77-89, 1968

24. Nair MPN, Schwartz SA: Suppression of natural killer activity and antibody-dependent cellular cytotoxicity by cultured human lymphocytes. J Immunol 126:2221-2229, 1981
25. Bloom ET, Korn EL: Quantification of natural cytotoxicity by human lymphocyte subpopulations isolated by density: Heterogeneity of the effector cells. J Immunol Meth 58:323-335, 1983

26. Nair MPN, Schwartz SA: Immunoregulation of lymphokine activated killer cells. Clin Immunol Immunopathol 49:28-40, 1988

27. Grossmann A, Ledbetter J, Rabinovitch P: Reduced proliferation in $\mathrm{T}$ lymphocytes in aged humans is predominantly in the CD8+ subset, and is unrelated to defects in transmembrane signaling which are predominantly in the CD4+ subset. Exp Cell Res 180:367-382, 1989

28. Murasko D, Nelson B, Silver R, et al: Immunologic response in an elderly population with a mean age of 85. Am J Med 81:612-618, 1986 